Check for updates

Cite this: RSC Adv., 2018, 8, 36412

\title{
Crystal structures of transition metal pernitrides predicted from first principles $\dagger$
}

\author{
Rongmei Yu, (D) ab Ermiao Sun, ${ }^{a}$ Liguang Jiao, ${ }^{a}$ Yongmao Cai, ${ }^{d}$ Hongbo Wang (D) *a \\ and Yansun $\mathrm{Yao}^{\mathrm{c}}$
}

We have extensively explored the stable crystal structures of early-transition metal pernitrides $\left(\mathrm{TMN}_{2}, \mathrm{TM}=\right.$ $\mathrm{Ti}, \mathrm{V}, \mathrm{Cr}, \mathrm{Mn}, \mathrm{Zr}, \mathrm{Nb}, \mathrm{Mo}, \mathrm{Hf}$, and Ta) at ambient and high pressures using effective CALYPSO global structure search algorithm in combination with first-principles calculations. We identified for the first time the ground-state structures of $\mathrm{MnN}_{2}, \mathrm{TaN}_{2}, \mathrm{NbN}_{2}, \mathrm{VN}_{2}, \mathrm{ZrN}_{2}$, and $\mathrm{HfN}_{2}$ pernitrides, and proposed their synthesis pressures. All predicted crystal structures contain encapsulated $\mathrm{N}_{2}$ dumbbells in which the two $\mathrm{N}$ atoms are singly bonded to a $\left[\mathrm{N}_{2}\right]^{4-}$ pernitride unit utilizing the electrons transferred from the transition metals. The strong nature of the single dinitrogen bond and transition metal-nitrogen charge transfer induce extraordinary mechanic properties in the predicted transition metal pernitrides including large bulk modulus and high Vickers hardness. Among the predictions the hardness of $\mathrm{MnN}_{2}$ is $36.6 \mathrm{GPa}$, suggesting that it is potentially a hard material. The results obtained in the present study are important to the understanding of structure-property relationships in transition metal pernitrides and will hopefully encourage future synthesis of these technologically important materials.

Received 20th September 2018
Accepted 19th October 2018

DOI: $10.1039 / c 8 r a 07814 a$

rsc.li/rsc-advances superhard material, which is about $100 \mathrm{GPa}$ higher than that of pure platinum. ${ }^{1}$ The extraordinary mechanical properties of TM pernitrides are associated with a particular structural motif. Although their crystal structures may be different, most TM pernitrides contain ultra-incompressible $\mathrm{N}_{2}$ dumbbells which are held together by strong covalent $\mathrm{N}-\mathrm{N}$ interaction. Albeit similar to the $\mathrm{N}_{2}$ molecule in geometry, these $\mathrm{N}_{2}$ dumbbells are single-bonded in nature, utilizing the electrons transferred from the TM atoms. The strength of the $\mathrm{N}-\mathrm{N}$ interactions in the $\mathrm{N}_{2}$ dumbbells are comparable to that in the single-bonded polymeric phase of nitrogen. ${ }^{9}$ As such, the nitrogen atoms in most TM pernitrides are octahedrally coordinated with TM atoms by strong, directional $\mathrm{TM}-\mathrm{N}$ bonds and form $\mathrm{TMN}_{6}$ octahedrons which are then interconnected through $\mathrm{N}-\mathrm{N}$ bonds in three dimensions. Clearly, knowing the crystal structures of TM pernitrides are very important for understanding their extraordinary mechanic properties, however, this is not always an easy task in experiment. A known difficulty is that X-ray diffraction is unable to determine the positions of the nitrogen atoms in TM nitrides due to the large $\mathrm{TM} / \mathrm{N}$ atomic mass ratio.

Meanwhile, many theoretical studies have been carried out to help resolving the crystal structures of TM pernitrides, and to predict new targets for future synthesis. The structure of $\mathrm{OsN}_{2}$ was determined to be isostructural to that of marcasite with orthorhombic Pnnm space group. ${ }^{10} \mathrm{PtN}_{2}$ and $\mathrm{PdN}_{2}$ were found to form in the cubic pyrite structure with the $P a \overline{3}$ space group. ${ }^{11}$ $\mathrm{RuN}_{2}$ and $\mathrm{RhN}_{2}$ were predicted to have marcasite structure as well ${ }^{10}$ which was then experimentally confirmed. ${ }^{5,6}$ The $\operatorname{IrN}_{2}$ was
Changchun, 130012, P. R. China.E-mail:whb2477@jlu.edu.cn

${ }^{b}$ College of Physics and Electronic Engineering, Nanyang Normal University, Nanyang, 473061, P. R. China

${ }^{c}$ Department of Physics and Engineering Physics, University of Saskatchewan, Saskatoon, Saskatchewan S7N 5E2, Canada

${ }^{d}$ School of Science, Northeast Electric Power University, Jilin, 132012, P. R. China

$\dagger$ Electronic supplementary information (ESI) available. See DOI: 10.1039/c8ra07814a 
predicted to be isostructural to $\mathrm{CoSb}_{2}$ or arsenopyrite ${ }^{\mathbf{1 0 , 1 2}}$ however the subsequently synthesized $\mathrm{IrN}_{2}$ has a baddeleyitetype structure. ${ }^{4}$ For $\mathrm{ReN}_{2}$, three structures were predicted as possible candidates, namely, rutile structure $\left(\mathrm{P}_{2} / \mathrm{mnm}\right),{ }^{13} \mathrm{Pbcn}$ structure, ${ }^{\mathbf{1 4}}$ and distorted rhenium diboride structure ( $P 4$ / mmm $),{ }^{15}$ but the synthesized $\mathrm{ReN}_{2}$ has the $\mathrm{MoS}_{2}$ structure. ${ }^{16}$ On early TM side, $\mathrm{MoN}_{2}$ was synthesized with a rhombohedral $\mathrm{MoS}_{2}$ structure. ${ }^{17}$ However, a theoretical study suggests that the thermodynamic ground state of $\mathrm{MoN}_{2}$ should have a hexagonal structure. ${ }^{18} \mathrm{TiN}_{2}$ has been predicted to have the tetragonal $\mathrm{CuAl}_{2}$-type structure $(14 / \mathrm{mcm})^{19}$ which was successfully synthesized soon after. ${ }^{7}$ It is noteworthy that the synthesized $\mathrm{TiN}_{2}$ has a very high bulk modulus of $385 \mathrm{GPa}^{7}$ In addition to the realized pernitrides, many others were predicted to exist as well, await for future synthesis. The long list includes $\mathrm{ZrN}_{2},{ }^{20} \mathrm{CrN}_{2},{ }^{21}$ $\mathrm{NbN}_{2},{ }^{22} \mathrm{HfN}_{2},{ }^{23} \mathrm{WN}_{2},{ }^{24}$ and others. ${ }^{25-27}$ Several new prototypic structures were proposed for TM pernitrides, including the pyrite-type, $P 6_{3} / m m c$ and $P \overline{6} m 2$ structures, some of which were suggested based on the structure analogy with chemically similar materials. Mechanic properties in particular the elasticity and hardness of TM pernitrides was one of the focal points of these investigations.

In the present study, we systematically explored the stable phases of TM pernitides adding several new ones $(\mathrm{TM}=\mathrm{Ti}, \mathrm{V}$, $\mathrm{Cr}, \mathrm{Mo}, \mathrm{Mn}, \mathrm{Zr}, \mathrm{Nb}, \mathrm{Hf}$, and $\mathrm{Ta}$ ). Some of these compounds have been studied before but the methods used based on known structure analogy may not guarantee finding the global minima of these phases, as shown in several cases above. To this end we employed a global structure search in combine with first principle calculations aiming to find the true thermodynamic ground states of these compounds. Since the laboratory synthesis of TM pernitrides often requires high pressure, the search is expanded from ambient to high pressures range up to $100 \mathrm{GPa}$. The $\mathrm{CrN}_{2}$ and $\mathrm{MoN}_{2}$ were found to have the same hexagonal structure $\left(P 6_{3} / m m c\right)$, while $\mathrm{MnN}_{2}$ has a $P \overline{1}$ structure. $\mathrm{TaN}_{2}$ is predicted to have an orthorhombic Cmca structure. For $\mathrm{NbN}_{2}$, the present study uncovers a new monoclinic structure (Cc) which is thermodynamically more stable than the previously proposed Cmca structure. $\mathrm{TiN}_{2}$ was found to have the $\mathrm{CuAl}_{2}$-type structure $(14 / \mathrm{mcm})$, which is in agreement with previous experimental and theoretical reports. In addition, $\mathrm{VN}_{2}$, $\mathrm{ZrN}_{2}$ and $\mathrm{HfN}_{2}$ were predicted to have the same CuAl 2 -type (I4/ $\mathrm{mcm}$ ) structure. All predicted TM pernitrides are thermodynamically stable with respect to decomposition to elemental TM and $\mathrm{N}_{2}$ at ambient pressure. $\mathrm{CrN}_{2}, \mathrm{MoN}_{2}$, and $\mathrm{MnN}_{2}$ are also found stable against decomposition to simple nitride TMN and $\mathrm{N}_{2}$ at ambient pressure. The established thermal stability suggests that the predicted TM pernitrides are likely synthesizable at high pressure and can be quench recovered at ambient conditions.

\section{Computational approaches}

The investigation of TM pernitrides consists of the determination of ground state crystalline structures and calculation of the properties of interest. The density functional theory (DFT) ${ }^{28}$ based calculations reported in the present work were carried out using the Vienna ab initio simulation package (VASP) ${ }^{\mathbf{2 9 , 3 0}}$ with the projector augmented wave scheme (PAW). ${ }^{31}$ The exchange correlation functional with the generalized gradient approximation (GGA) of Perdew-Burke-Ernzerhof (PBE) ${ }^{32}$ was used to solve the Kohn-Sham equations. Global crystal structure searches for TM pernitrides were performed using the particleswarm optimization (PSO) algorithm for structural prediction as implemented in the CALYPSO code, which has been proved to be effective and accurate in predicting the crystal structures of a large variety of materials..$^{33,34}$ The structure searches were performed using the CALYPSO code in combination with DFT total energy calculations and system sizes ranging from 1 to 4 formula units (f.u.) per simulation cell at several pressure points in the pressure range of 0-100 GPa. The obtained lowenthalpy structures were then further optimized using more strict more convergence criteria with a kinetic energy cutoff of $750 \mathrm{eV}$ and $k$-point meshes of spacing $2 \pi \times 0.03 \AA^{-1}$ for Brillouin zone integration. The energy convergence with respect to these parameters was set to be better than $1 \mathrm{meV}$ per atom. Phonon dispersion relations were calculated on the basis of the supercell approach by using the PHONOPY package. ${ }^{35}$ A $2 \times 2 \times$ 2 supercell was constructed for $\mathrm{VN}_{2}, \mathrm{ZrN}_{2}, \mathrm{HfN}_{2}$, and $\mathrm{MnN}_{2}, 3 \times$ $3 \times 3$ for $\mathrm{NbN}_{2}$ and $2 \times 1 \times 2$ for TaN $\mathrm{T}_{2}$ to calculate forces. Bulk modulus, shear modulus, Young's modulus, and Poisson's ratio were estimated by using Voigt-Reuss-Hill approximation. ${ }^{36}$ Chemical bonding analyses for the crystal structures of interest were carried out by means of the crystal orbital Hamilton population (COHP) method implemented in the LOBSTER program package. ${ }^{37,38}$

\section{Results and discussion}

The most energetically favored crystal structure for each TM pernitride of interest was successfully obtained from the global structure search. The enthalpies for these structures $(H)$ were calculated in the pressure range 0-100 GPa, and compared to the enthalpies of the decomposition products along two possible decomposition routes:

$$
\begin{aligned}
& \Delta H_{\mathrm{f}(\mathrm{I})}=H_{\mathrm{TMN}_{2}}-H_{\mathrm{TM}}-H_{\mathrm{N}_{2}} \\
& \Delta H_{\mathrm{f}(\mathrm{II})}=H_{\mathrm{TMN}_{2}}-H_{\mathrm{TMN}}-\frac{1}{2} H_{\mathrm{N}_{2}}
\end{aligned}
$$

The route (1) describes the decomposition to elemental TM and solid $\mathrm{N}_{2}$, while route (2) is for the decomposition to simple TM nitride (TMN) and solid $\mathrm{N}_{2}$. The relative enthalpy of formation $\Delta H_{\mathrm{f}}$ has been calculated using the lowest-enthalpy structures of $\mathrm{TMN}_{2}, \mathrm{TMN}$, and $\mathrm{N}_{2}$ previously known or obtained from the structure searches as reference structures (see ESI $\dagger$ for details). The results shown in Fig. 1 reveal that all predicted structures of TM pernitrides are thermodynamically stable against the decomposition route (1) at ambient pressure (shown by negative $\Delta H_{\mathrm{f}}$ ). For decomposition route (2), the $\mathrm{CrN}_{2}$, $\mathrm{MoN}_{2}$, and $\mathrm{MnN}_{2}$ are stable at ambient pressure. The rest TM pernitrides are thermodynamically unstable at ambient pressure but quickly become stable at moderate pressures (4.74- 
(a)

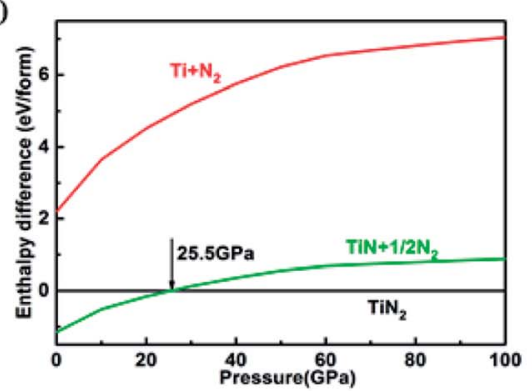

(d)

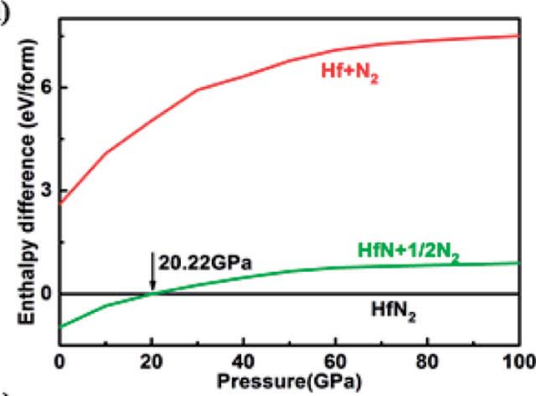

(g)

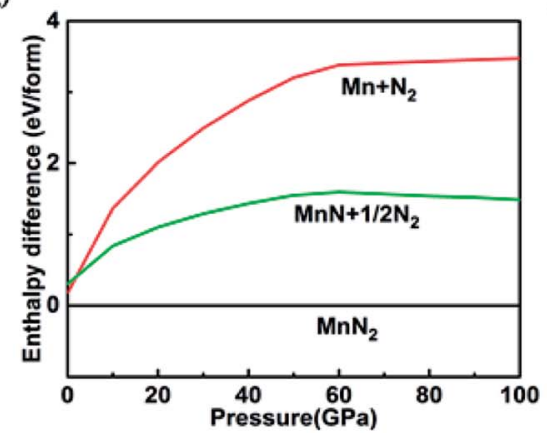

(b)

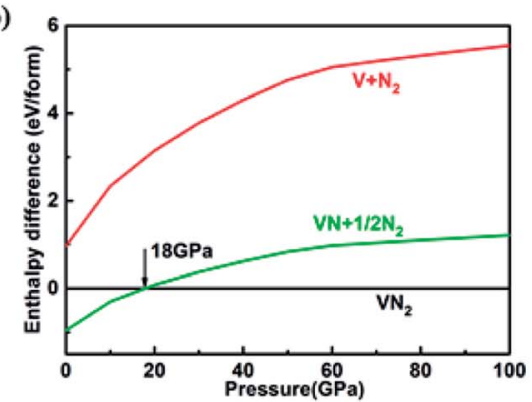

(e)

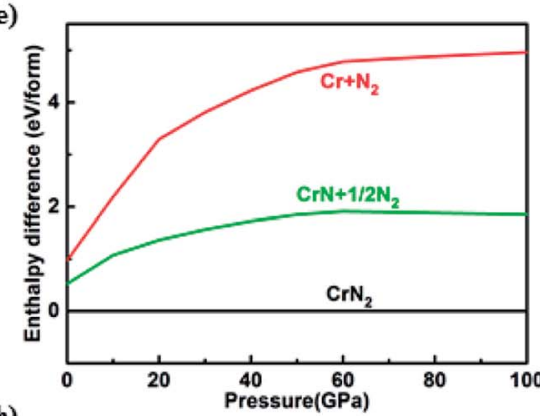

(h)

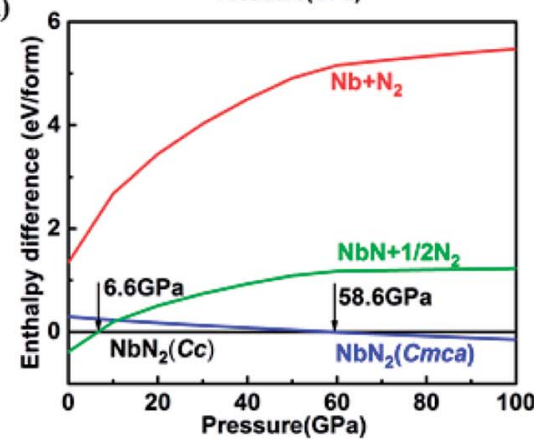

(c)

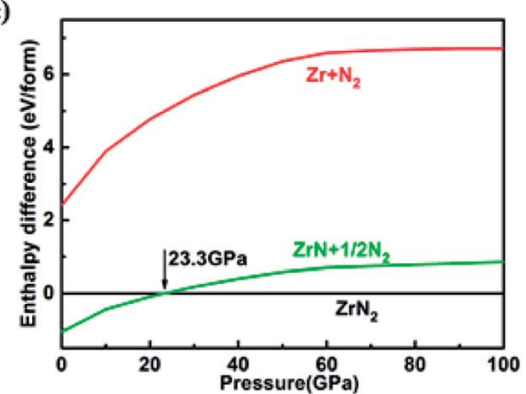

(f)

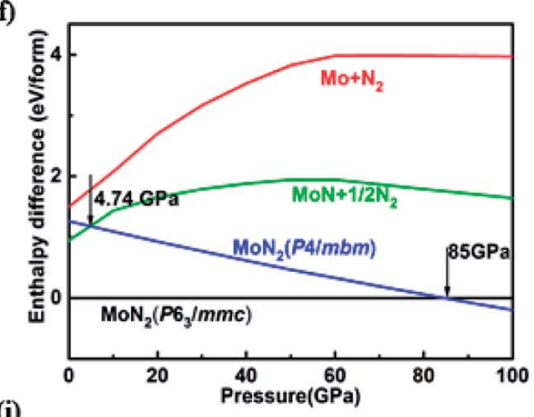

(i)

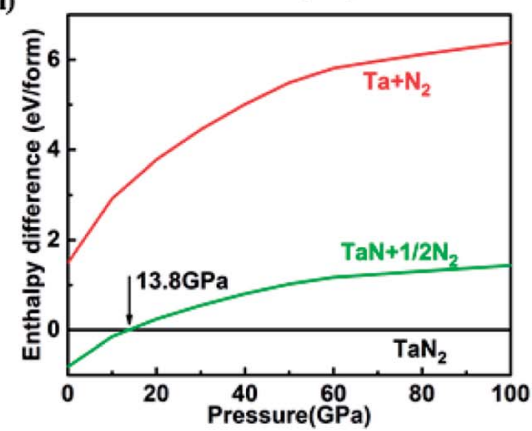

Fig. 1 Pressure-dependent enthalpy differences between $\mathrm{TMN}_{2}$ pernitrides and two mixtures: (red) elemental TM and solid $\mathrm{N}_{2}$, and (green) TMN mononitride and $1 / 2$ solid $N_{2}$. Possible phase transitions under high pressure are predicted for $\mathrm{MoN}_{2}$ and $\mathrm{NbN}_{2}(\mathrm{blue})$.

25.5 GPa). The calculated $\Delta H_{\mathrm{f}(\mathrm{I})}$ and $\Delta H_{\mathrm{f}(\mathrm{II})}$ are listed in Table 1. The proposed pressures of formation for these nitrides (arrows in Fig. 1) are well within the reach of current high-pressure synthesis, which provides a good chance that they can be synthesized under high pressure and then quench recovered to ambient conditions. Among these nitrides the $\mathrm{TiN}_{2}$ has already been realized in laboratory at pressures at a pressure of $73 \mathrm{GPa}^{7}$ Although the starting materials (TiN and $\mathrm{N}_{2}$ ) and product (I4/ $m \mathrm{~cm} \mathrm{TiN}_{2}$ ) are the same, the calculated pressure for its formation is $25.5 \mathrm{GPa}$, which is lower than the experimental pressure

Table 1 Calculated equilibrium lattice parameters, $a_{0}(\AA), b_{0}(\AA)$ and $c_{0}(\AA)$, equilibrium volume per f.u., $V_{0}\left(\AA^{3}\right)$, bonding length of $d_{T M-N}(\AA)$ and $d_{\mathrm{N}-\mathrm{N}}(\AA)$, formation enthalpies of the two reaction routes $H_{\mathrm{f}(\mathrm{I})}$ and $H_{\mathrm{f}(I)}$, and Vickers hardness for the $\mathrm{TMN}_{2}$ pernitrides predicted in the present study. Comparison is made to previously reported results where possible

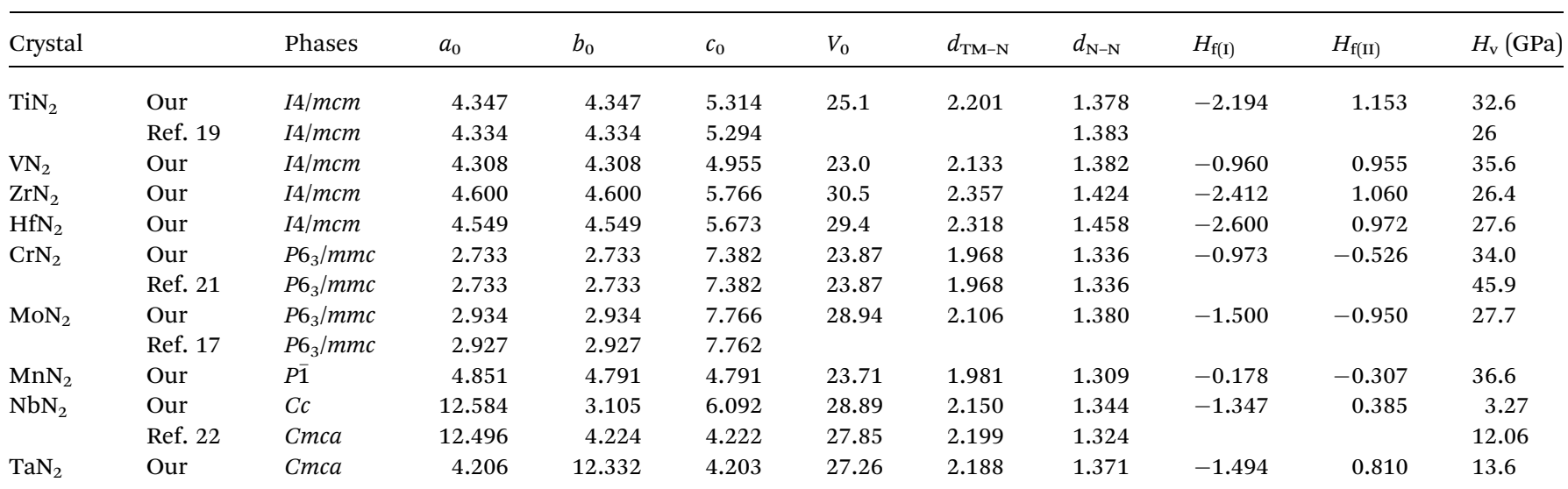


by about $50 \mathrm{GPa}$. The large discrepancy is mainly attributed to the known large energy barrier associated with the formation of TM pernitrides. To overcome the barrier, high temperature is usually required for the synthesis. Thus, we expect moderated higher formation pressures than what calculated here for all predicted TM pernitrides.

The crystal structure and optimized lattice parameters of the predicted TM pernitrids are shown in Fig. 2 and Table 1. For previously synthesized $\mathrm{TiN}_{2}$, our structure search correctly produces its structure at ambient and high pressures, the $\mathrm{CuAl}_{2}-$ type structure $(I 4 / \mathrm{mcm})$ (Fig. 2a). The calculated lattice parameters are $a=4.35 \AA, c=5.31 \AA$, very close to the experimental values, $a=4.33 \AA$ and $c=5.29 \AA$. $^{7}$ For $\mathrm{CrN}_{2}$, which has yet to be synthesized, we predict its ground state is a hexagonal structure with the $\mathrm{PG}_{3} / \mathrm{mmc}$ structure (Fig. 2e). This prediction agrees with a previous theoretical report. ${ }^{21}$ The $P 6_{3} / m m c$ structure is the lowest enthalpy phase of $\mathrm{CrN}_{2}$ from ambient pressure to at least $100 \mathrm{GPa}$, the highest pressure used in the present study. The $\mathrm{PG}_{3} /$ $m m c$ structure is consisting of $\mathrm{MoS}_{2}$-type $\mathrm{CrN}_{2}$ slabs stacked by covalent $\mathrm{N}-\mathrm{N}$ bonds with an ABA sequence (Fig. 2e). If the $\mathrm{N}_{2}$ units are considered as a single entity, this structure would reduce to a NiAs-type hexagonal structure. The $\mathrm{N}-\mathrm{N}$ distance within the $\mathrm{N}_{2}$ units is $1.336 \AA$, which is much longer than the bondlength in triply bonded $\mathrm{N}_{2}$ molecule $(1.10 \AA)$. The bondlength in the $\mathrm{N}_{2}$ units is close to that of a single bond in hydrazine (1.45 $\mathrm{\AA})$, and longer than that of a double bond in dinitrogen difluoride $(1.21 \AA)$. Thus, we may consider the $\mathrm{N}_{2}$ unit singly bonded, formally a $\left[\mathrm{N}_{2}\right]^{4-}$ anion. The $\mathrm{CrN}_{2}$ is nominally a charge transfer $\mathrm{Cr}^{4+} \mathrm{N}_{2}{ }^{4-}$, which should form a semiconducting state. The $\mathrm{PG}_{3} / \mathrm{mmc}$ structure is also the ground state structure for $\mathrm{MoN}_{2}$ at ambient pressure. A phase transition is predicted for $\mathrm{MoN}_{2}$ at $85 \mathrm{GPa}$, at where it transforms to a $P 4 / \mathrm{mbm}$ structure. This prediction agrees with previous theoretical study as well. ${ }^{18}$ The experimentally discovered $\mathrm{MoS}_{2}$ structure of $\mathrm{CrN}_{2}$ (ref. 17) was calculated to be a metastable phase. The $P 4 / \mathrm{mbm}$ structure contains $\mathrm{MoN}_{8}$ cuboids that are interconnected by edge-sharing and staked along the perpendicular direction through Mo-N bonds. The $\mathrm{N}_{2}$ dumbells are still retained in the $\mathrm{P} 4 / \mathrm{mbm}$ structure and singly bonded. Unlike $\mathrm{CrN}_{2}$ and $\mathrm{MoN}_{2}$, the other stable pernitride $\mathrm{MnN}_{2}$ has a low symmetry monoclinic $P \overline{1}$ structure. In this structure, the $\mathrm{Mn}$ atom is octahedrally coordinated with six $\mathrm{N}$ atoms to $\mathrm{MN}_{6}$ octahedra that are interconnected through $\mathrm{N}-\mathrm{N}$ bonds. The bondlength of the $\mathrm{N}-\mathrm{N}$ bonds is $1.31 \AA$, similar to those in $\mathrm{CrN}_{2}$ and $\mathrm{MoN}_{2}$.

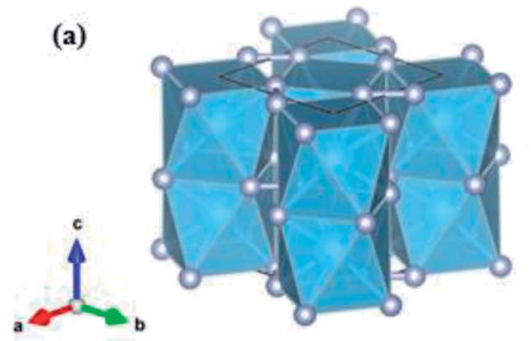

(d)

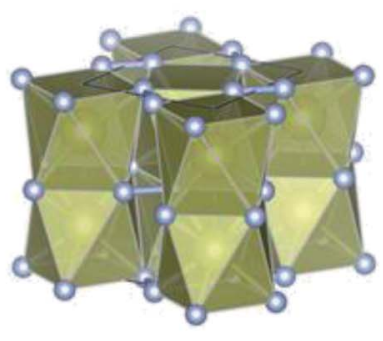

(g)

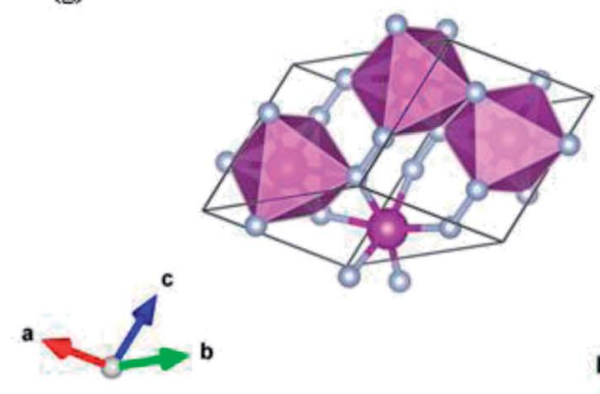

(b)

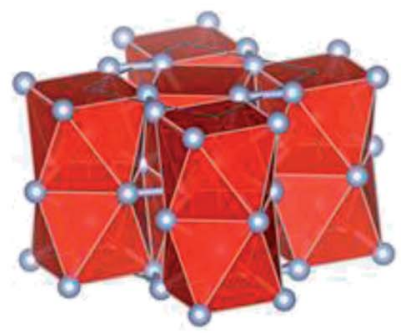

(e)

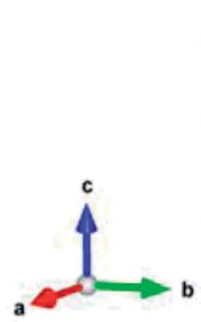

(h)

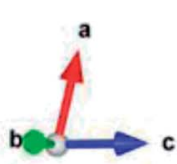

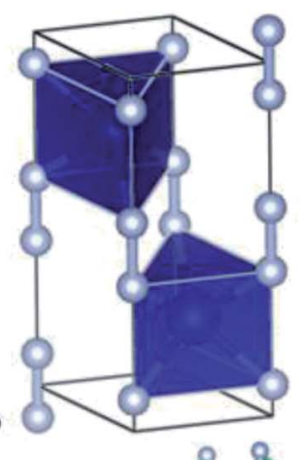

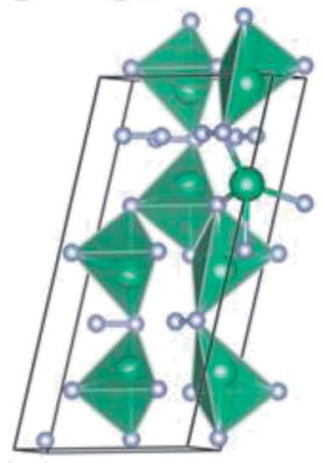

(c)

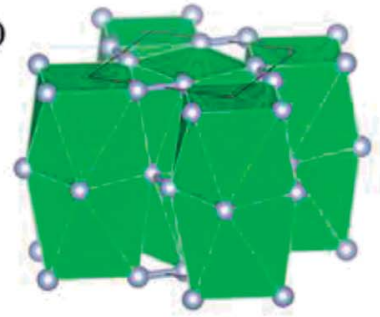

(f)

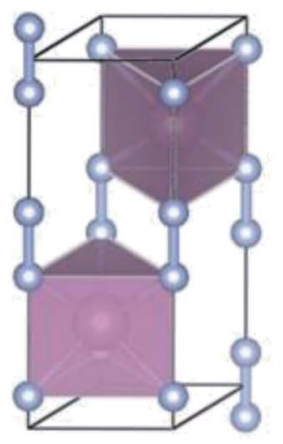

(i)

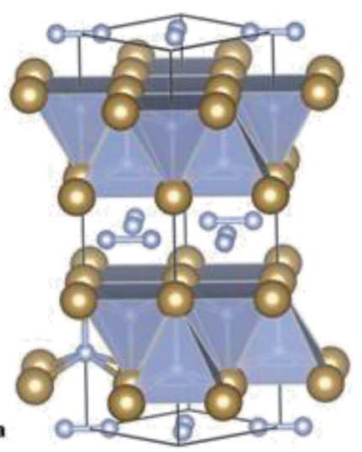

Fig. 2 Crystal structures for (a) $14 / m c m-\mathrm{TiN}_{2}$, (b) $14 / m c m-\mathrm{VN}_{2}$, (c) $14 / m c m-\mathrm{ZrN}_{2}$, (d) $14 / m c m-H f N_{2}$, (e) $P 6_{3} / m m c-\mathrm{CrN}_{2}$, (f) $P 6_{3} / m m c-M o N_{2}$, (g) $P 1-\mathrm{MnN}_{2}$, (h) $\mathrm{Cc}-\mathrm{NbN}_{2}$, and (i) $\mathrm{Cmca}_{-}-\mathrm{TaN}_{2}$. All structures are optimized at $\mathrm{O} \mathrm{GPa}$. Large and small spheres denote TM and $\mathrm{N}$ atoms, respectively. 
The $\mathrm{NbN}_{2}$ and $\mathrm{TaN}_{2}$ compounds have been previously investigated theoretically, ${ }^{\mathbf{2 4 , 2 7}}$ and several candidate structures were proposed based on educated guesses from known structures of chemically similar compounds. The considered structures include $P 6_{3} / m m c, P \overline{6} m 2, P a \overline{3}$, pyrite and fluorite structures. In the present study, however, we found none of this structure corresponding to the ground state of $\mathrm{NbN}_{2}$ and $\mathrm{TaN}_{2}$. The predicted ground state of $\mathrm{TaN}_{2}$ has the Cmca space group instead. In this structure, the Ta and $\mathrm{N}$ are sandwiched to form distorted $\mathrm{TaN}_{5}$ quadrangular pyramid which are extended to two dimensional slabs with shared edges. The slabs are intercalated with the $\mathrm{N}_{2}$ dimers along the $c$-axis (Fig. 2i). According to the $\mathrm{N}-\mathrm{N}$ bondlength, i.e., $1.37 \AA$, the $\mathrm{N}_{2}$ dimers are singly bonded. The Cmca structure is predicted to form at pressures above 13.8 $\mathrm{GPa}$ and stays stable to at least $100 \mathrm{GPa}$. For $\mathrm{NbN}_{2}$, our structure search establishes a monoclinic structure with the $C c$ space group as its ground state at ambient pressure. The previously proposed $\mathrm{Cmca}$ structure ${ }^{22}$ is found to have slightly higher enthalpy, e.g., $\sim 29.2 \mathrm{meV}$ f.u. ${ }^{-1}$ at ambient pressure. On the other hand, the Cmca structure is more stable at high pressures which surpasses the $C c$ structure at $58.6 \mathrm{GPa}$ to become the thermodynamic ground state (Fig. 1h).

To date, $\mathrm{VN}_{2}, \mathrm{ZrN}_{2}$ and $\mathrm{HfN}_{2}$ have not been synthesized. In a previous theoretical study, ${ }^{23} \mathrm{ZrN}_{2}$ and $\mathrm{HfN}_{2}$ are assumed to have the same ground state structure as $\mathrm{TiN}_{2}$ since the three TMs are in the same group in the periodic table. Our structure search confirmed this conjecture. Both $\mathrm{ZrN}_{2}$ and $\mathrm{HfN}_{2}$ adopt the $\mathrm{CuAl}_{2}$-type structure $(\mathrm{I} / \mathrm{mcm})$ and no phase transitions are found over the entire pressure range investigated (0-100 GPa). A unique feature of the $14 / \mathrm{mcm}$ structure is that the TM and $\mathrm{N}$ atoms form $\mathrm{TMN}_{8}$ face-sharing tetragonal antiprisms, rather than $\mathrm{TMN}_{6}$ octahedrons commonly seen in $\mathrm{TM}$ pernitrides (Fig. 2). The neighboring antiprism are connected through $\mathrm{N}_{2}$ dumbbells along $a$ - and $b$-axis. The $\mathrm{N}-\mathrm{N}$ bondlengths are 1.42 and $1.46 \AA$, respectively, for $\mathrm{ZrN}_{2}$ and $\mathrm{HfN}_{2}$. These values are very close to the ideal length of single nitrogen bond (1.45 $\AA$ ) and those observed in some transition metal pernitrides such as $\mathrm{PtN}_{2}(1.41 \AA)$ and $\mathrm{OsN}_{2}(1.43 \AA) .{ }^{2,3}$ This indicates that the $\mathrm{N}_{2}$ dumbbells are singly bonded with a nominal $\left[\mathrm{N}_{2}\right]^{4-}$ state, which is isoelectronic to difluorine $\mathrm{F}_{2}(1.43 \AA)$. The previously unknown $\mathrm{VN}_{2}$ is predicted to have the same $14 / \mathrm{mcm}$ structure with slightly shorter $\mathrm{N}-\mathrm{N}$ bondlength $(1.38 \AA$ ) .

In view of the pernitride structures described above, $\mathrm{TiN}_{2}$ and $\mathrm{VN}_{2}$ have almost same $\mathrm{N}-\mathrm{N}$ bond lengths (1.37 $\AA$ and $1.38 \AA$ ), but $\mathrm{ZrN}_{2}$ and $\mathrm{HfN}_{2}$ have longer bond lengths (1.42 $\mathrm{A}, 1.46 \AA$ ), suggesting the presence of more 'soften' $\mathrm{N}_{2}$ in the latter. Clearly, the bondlength here is an indicator of bonding interaction, where the 'shorter bond equals stronger bond' conjecture prevails. For $\mathrm{N}_{2}$ quasimolecules, specifically, this also reveals the degree of electron sharing between two $\mathrm{N}$ atoms, from triply bonded $\mathrm{N}_{2}$, to doubly bounded $\left[\mathrm{N}_{2}\right]^{2-}$, and to singly bonded $\left[\mathrm{N}_{2}\right]^{4-}$. The amount of electrons transferred from the transition metal therefore determines the bonding type, and ultimately determine the crystal structure. This is manifested by the fact that the Vickers hardness of the 3d TM pernitrides (32.6 GPa $\left(\mathrm{TiN}_{2}\right), 35.6 \mathrm{GPa}\left(\mathrm{VN}_{2}\right)$ ) are in general higher than those of $4 \mathrm{~d}$ and $5 \mathrm{~d}$ TM pernitrides $(26.4 \mathrm{GPa}$ $\left.\left(\mathrm{ZrN}_{2}\right), 27.6 \mathrm{GPa}\left(\mathrm{HfN}_{2}\right)\right)$. The dynamical stability of the predicted TM pernitrides are verified by the analysis of phonon-dispersion relations in the pressure range of 0-100 GPa (Fig. 3).

Among which, the dynamical stability of $\mathrm{TiN}_{2}, \mathrm{CrN}_{2}$, and $\mathrm{MoN}_{2}$ have already been established in previous theoretical studies. ${ }^{\mathbf{1 8 , 1 9 , 2 1}}$ The new pernitrides predicted in the present study, namely, $\mathrm{VN}_{2}$, $\mathrm{ZrN}_{2}, \mathrm{HfN}_{2}, \mathrm{MnN}_{2}, \mathrm{NbN}_{2}$, and $\mathrm{TaN}_{2}$, are confirmed dynamically stable from ambient pressure to their thesis pressure, by the absence of imaginary phonon frequency in the entire BZ (Fig. 3). The dynamic stabilities of predicted pernitrides provide a very strong case that they can be recovered at ambient conditions once synthesized under high pressure and high temperature. (a)

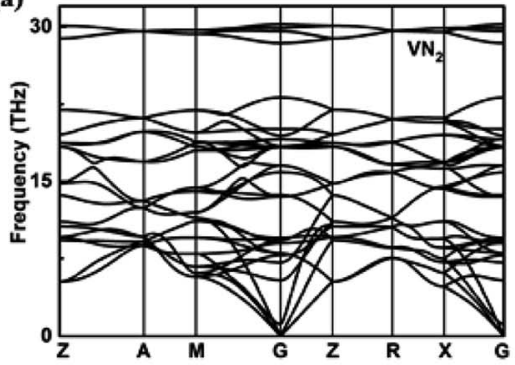

(d)

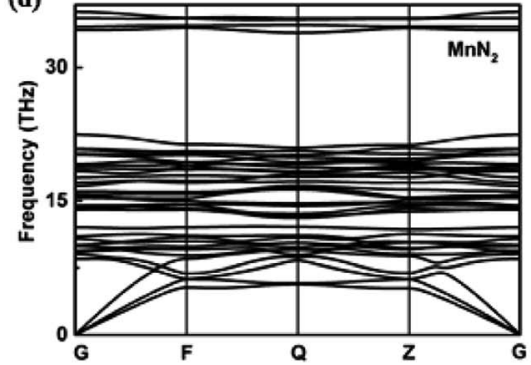

(b)

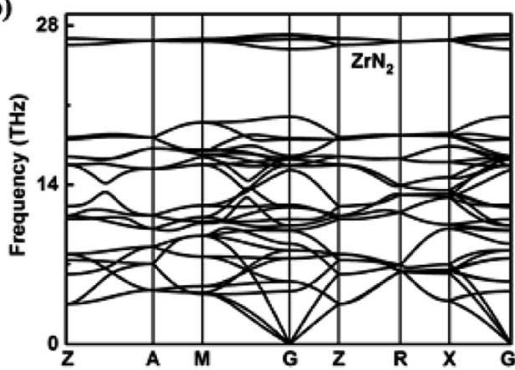

(e)

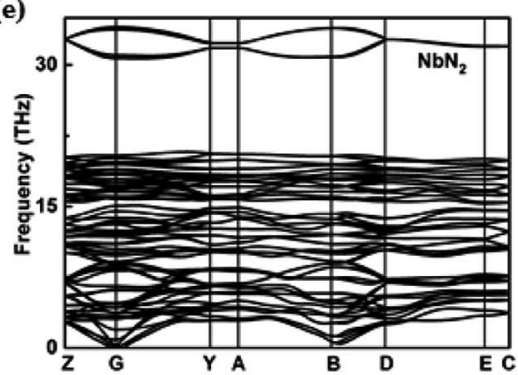

(c)

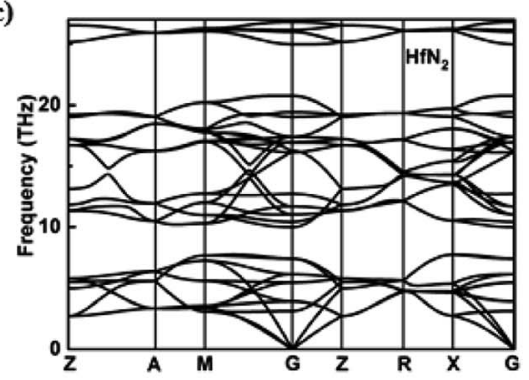

(f)

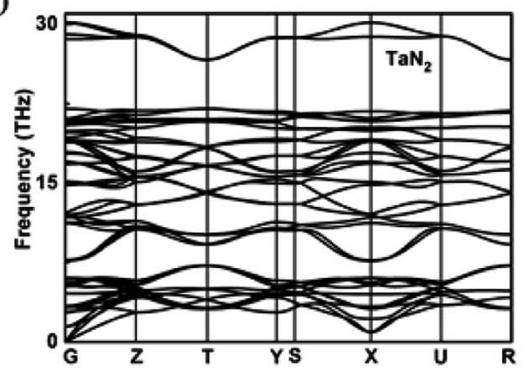

Fig. 3 Phonon dispersion relations for (a) $14 / m c m-\mathrm{VN}_{2}$, (b) $14 / m c m-\mathrm{ZrN}_{2}$, (c) $14 / m c m-\mathrm{HfN}_{2}$, (d) $P 1-\mathrm{MnN}_{2}$, (e) $C c-\mathrm{NbN}_{2}$, and (f) $C m c a-T a N_{2}$ calculated at ambient pressure along high symmetry directions in the Brillouin zone. 

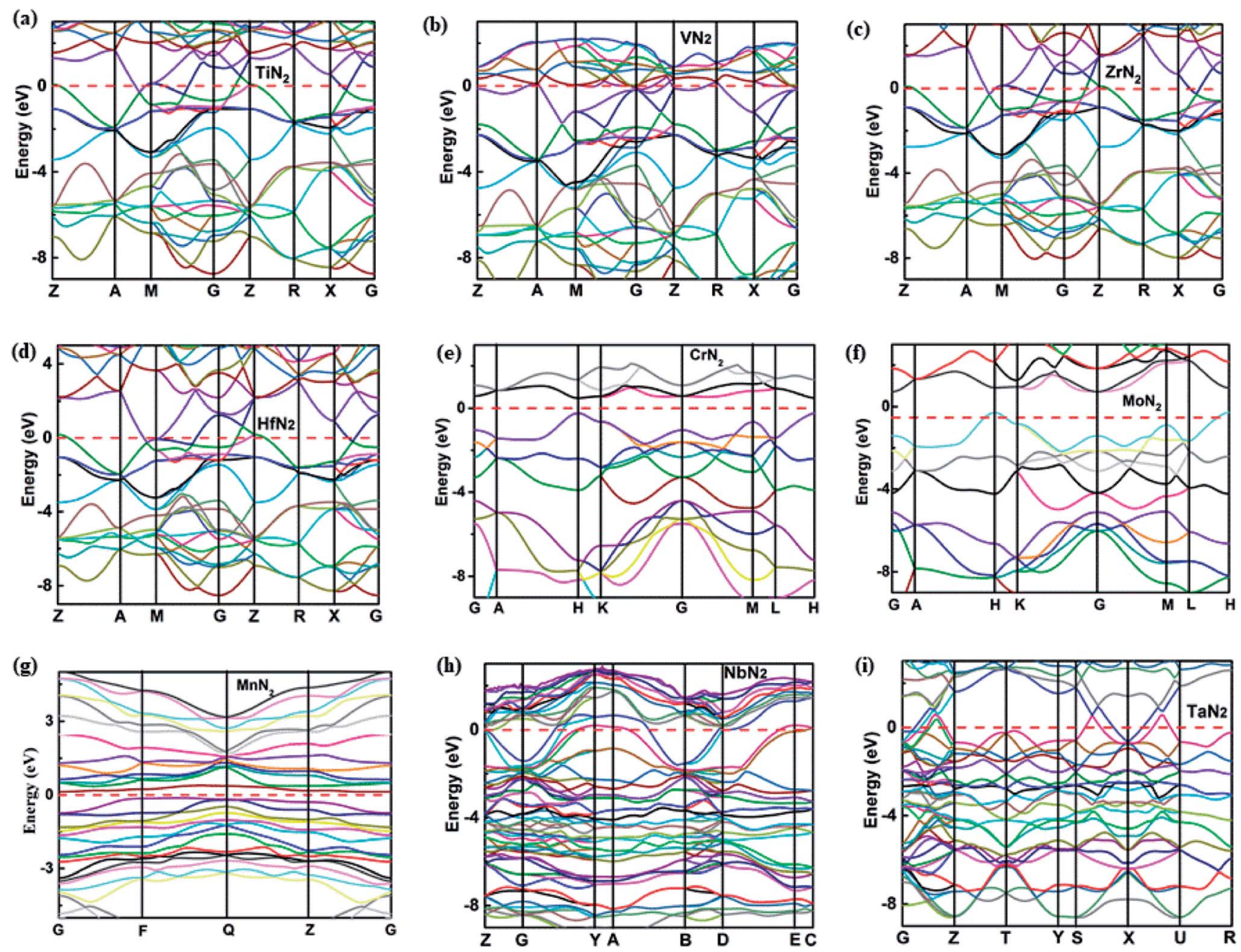

Fig. 4 Calculated band structures of TM pernitrides for (a) $14 / m c m-T i N_{2}$, (b) $14 / m c m-\mathrm{VN}_{2}$, (c) $14 / m c m-\mathrm{ZrN}_{2}$, (d) $14 / \mathrm{mcm}-\mathrm{HfN}{ }_{2}$, (e) $P 6_{3} / m m c$ $\mathrm{CrN}_{2}$, (f) $P 6_{3} / m m c-\mathrm{MoN}_{2}$, (g) $P 1-\mathrm{MnN}_{2}$, (h) $\mathrm{Cc}_{\mathrm{N}}-\mathrm{NbN}_{2}$, (i) $C m c a-\mathrm{TaN}_{2}$ at ambient pressure. The Fermi level (EF) is marked by red dashed line.

To understand the electronic properties and bonding features of these pernitrides, we have calculated their electronic band structure and density of states (DOS) at ambient pressure. The results are presented in Fig. 4 and 5. From the band structures and DOS, all compounds having the $I 4 / \mathrm{mcm}$ structure ( $\mathrm{TiN}_{2}, \mathrm{VN}_{2}, \mathrm{ZrN}_{2}$, and $\left.\mathrm{HfN}_{2}\right)$, the $C c$ structure $\left(\mathrm{NbN}_{2}\right)$ and the Cmca structure $\left(\mathrm{TaN}_{2}\right)$ are metallic owing to the finite DOS at the Fermi level due to multiple bands crossing. Projected DOS reveals that the electronic states at the Fermi level are dominated by the $\mathrm{d}$ electrons of TM and $\mathrm{p}$ electrons of $\mathrm{N}$ (Fig. 5). In particular, there are strong orbital hybridization between the $\mathrm{d}$ orbital of TM and $\mathrm{p}$ orbital of $\mathrm{N}$ in the energy range from -10 to $0 \mathrm{eV}$, indicating the interactions between $\mathrm{TM}$ and $\mathrm{N}$ are covalent in nature. Moreover, in most of the pernitrides the total DOS has a minimum value at the Fermi level (pseudo gap), which limits the possibility of achieving credible electrical conductivity, but the tendency of opening a band gap at the Fermi level is seen as a stabilization to the structures due to strong interactions between $\mathrm{TM}$ and $\mathrm{N}$. The $\mathrm{VN}_{2}$ is an exception in which the Fermi level shifts toward higher energy range and lies outside the pseudogap with relative higher electronic density of states. On the other hand, the compounds with the
$P 6_{3} / m c m$ structure $\left(\mathrm{CrN}_{2}\right.$ and $\left.\mathrm{MoN}_{2}\right)$ and $P \overline{1}$ structure $\left(\mathrm{MnN}_{2}\right)$ are semiconductors. In particular the $\mathrm{CrN}_{2}$ is predicted as a direct band gap semiconductor with the band gap of $0.51 \mathrm{eV}$. The other two pernitrides have indirect band gaps, i.e., $0.38 \mathrm{eV}$ for $\mathrm{MoN}_{2}$ and $1.0 \mathrm{eV}$ for $\mathrm{MnN}_{2}$, respectively.

Further analysis of chemical bonding in these pernitride has been carried out through crystal orbital Hamilton population (COHP) analysis (Fig. 6). COHP partitions the band-structure energy into different orbital-pair interactions, which can be used to index bonding, nonbonding, and antibonding contributions to the band-structure. Similar to the crystal-orbital overlap population (COOP), the COHP analysis provides a quantitative measure of the bond strengths in crystal structures by the -COHP values, where the positive and negative signs represent bonding and antibonding states, respectively. Here we draw positive -COHP values to the right and negative ones to the left, so the spikes on the left/right hand side correspond to antibonding/bonding states. In general, for TM$\mathrm{N}$ interactions in predicted pernitrides the antibonding states show up in the unoccupied crystal orbitals well above the Fermi level (dotted horizontal zero line), whereas for $\mathrm{N}-\mathrm{N}$ interactions, the antibonding $1 \pi_{\mathrm{g}}^{*}$ states are primarily between $-4 \mathrm{eV}$ and the 
(a)

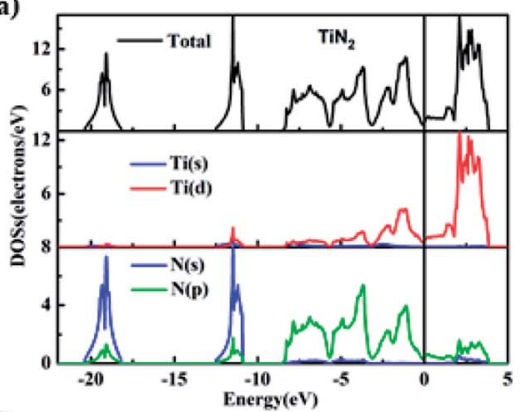

(d)

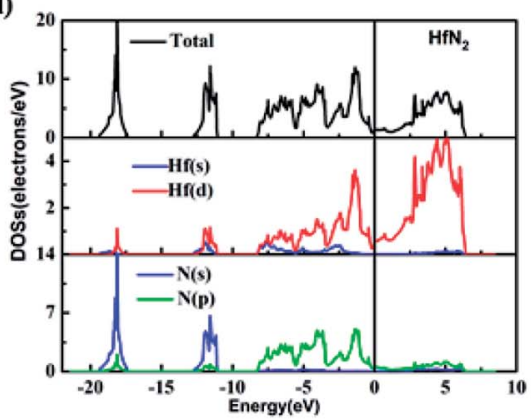

(g)

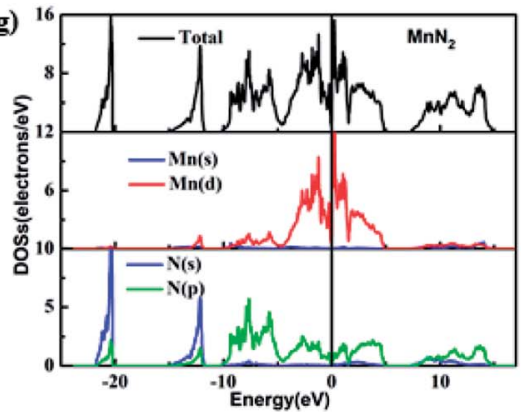

(b)

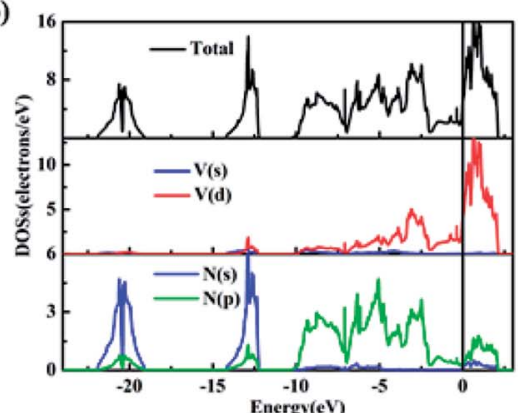

(e)

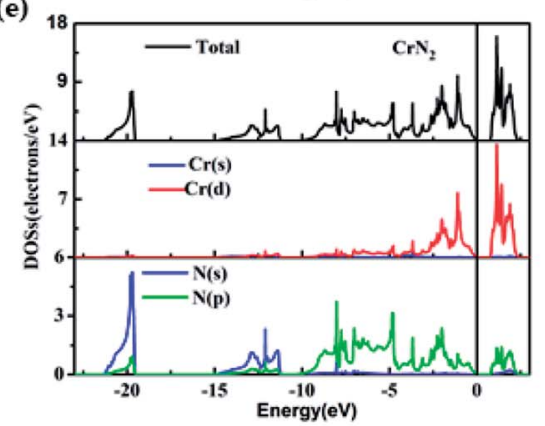

(h)

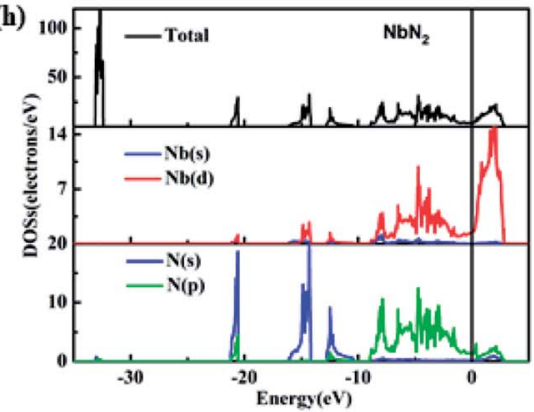

(c)

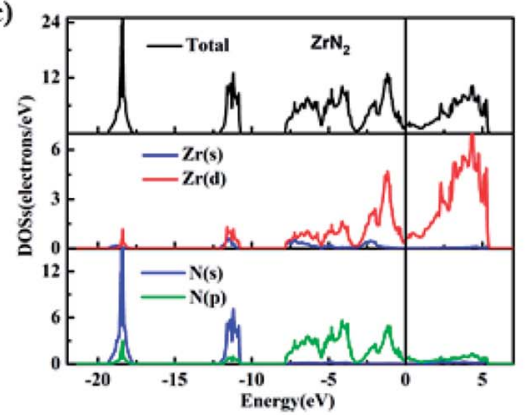

(f)

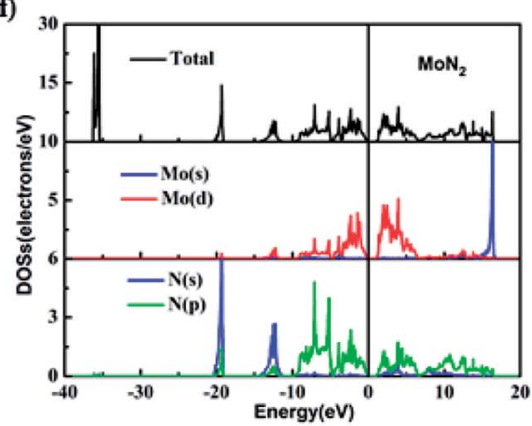

(i)

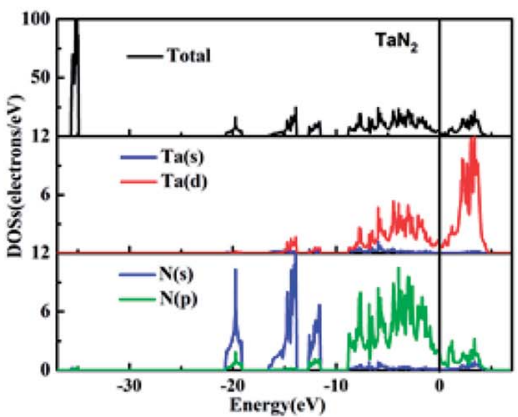

Fig. 5 Calculated total and partial density of states for TM pernitrides. (a) $14 / m c m-\mathrm{TiN}_{2}$, (b) $14 / m c m-\mathrm{VN}_{2}$, (c) $14 / m c m-Z r N_{2}$, (d) $14 / m c m-\mathrm{HfN}$, (e) $P 6_{3} / m m c-\mathrm{CrN}_{2}$, (f) $P 6_{3} / m m c-\mathrm{MoN}_{2}$, (g) $P 1-\mathrm{MnN}_{2}$, (h) $\mathrm{Cc}-\mathrm{NbN}_{2}$, (i) $\mathrm{Cmca}-\mathrm{TaN}_{2}$ at ambient pressure. The vertical line at origin is the Fermi level (E $E_{\mathrm{F}}$ ).

Fermi level. This is a significant finding, that the $1 \pi_{g}^{*}$ states are mostly occupied in $\mathrm{TMN}_{2}$ pernitrides. For neutral $\mathrm{N}_{2}$ molecule, the $1 \pi_{g}^{*}$ states are completely empty, resulting in exceedingly strong triple bonds. Adding two electrons to the $1 \pi_{\mathrm{g}}^{*}$ states would result in double-bonded $\left[\mathrm{N}_{2}\right]^{2-}$, which is isoelectronic to $\mathrm{O}_{2}$. Adding two more electrons would fully occupy the $1 \pi_{\mathrm{g}}^{*}$ states and produce single-bonded $\left[\mathrm{N}_{2}\right]^{4-}$, which is isoelectronic to $\mathrm{F}_{2}$. As demonstrated in previous work, ${ }^{39}$ for the case of $\mathrm{PtN}_{2}$, electrons transferred from Pt to $\mathrm{N}$ results in the full filling of antibonding $1 \pi_{\mathrm{g}}^{*}$ states for which a plausible electronic formulation should be $\mathrm{Pt}^{4+}\left[\mathrm{N}_{2}\right]^{4-}$. This single-bond scenario is also applicable to predicted pernitrides $\mathrm{TMN}_{2}$, as seen from the results of the COHP analysis and very similar $\mathrm{N}-\mathrm{N}$ bondlengths in $\mathrm{TMN}_{2}$ matching to that of F-F distance (1.42 $\AA$ ), although the exact occupation of the $1 \pi_{g}^{*}$ states may vary in different $\mathrm{TMN}_{2}$ pernitrides. ${ }^{7,19}$ This is fundamentally different from alkaline-earth pernitrides such as $\mathrm{BaN}_{2},{ }^{40}$ and $\mathrm{SrN}_{2}$ (ref. 41) which only contain double-bonded $\left[\mathrm{N}_{2}\right]^{2-}$ units.

Previously, it is suggested that the extraordinary mechanical properties and hardness of TM pernitrides are induced by the single nature of dinitrogen bond and charge transfer from TM to N. In opposite, BaN and SrN have only two electrons in the
$1 \pi_{\mathrm{g}}^{*}$ states and therefore exhibit much smaller hardness. ${ }^{39}$ The charge transfer controls the length of the single bond by providing Coulomb repulsion between two $\mathrm{N}$ atoms, and influences the bulk modulus. ${ }^{26}$ As the predicted TM pernitrides fall into this category, it is interesting to examine their mechanic properties and hardness. The total Vickers hardness $\left(H_{\mathrm{v}}\right)$ of a compound is expressed as the geometric average of the hardnesses of individual bonds,

$$
H_{\mathrm{v}}=\left[\prod_{\mu}\left(H_{\mathrm{v}}{ }^{\mu}\right)^{n^{\mu}}\right]^{\frac{1}{\sum^{n^{\mu}}},}
$$

where $n^{\mu}$ is the number of bond for the $\mu$ th bonding type in the crystal, and $H_{\mathrm{v}}{ }^{\mu}$ is the Knoop hardness for covalent and polar covalent crystals, ${ }^{42}$

$$
H_{\mathrm{v}}^{\mu}(\mathrm{GPa})=423.8 N_{\mathrm{v}} X_{\mathrm{ab}} \mathrm{e}^{-2.7 f_{\mathrm{i}}}-3.4
$$

The calculated Vickers hardness of predicted $\mathrm{TMN}_{2}$ pernitrides are shown in Table 1. It is worth noting that $\mathrm{MnN}_{2}$ has the highest hardness (36.6 GPa) among them, while $\mathrm{VN}_{2}$ has a near 
(a)

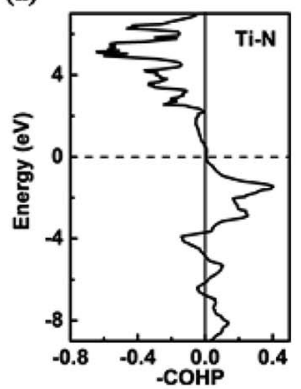

(d)

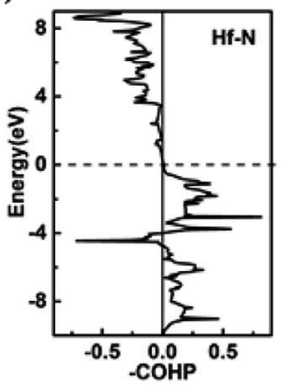

(g)

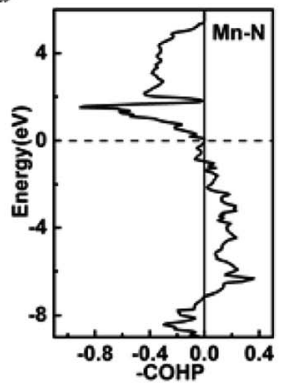

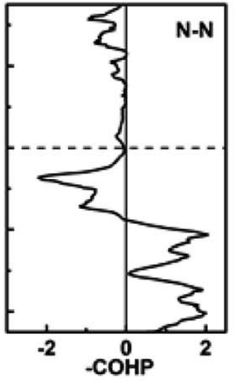

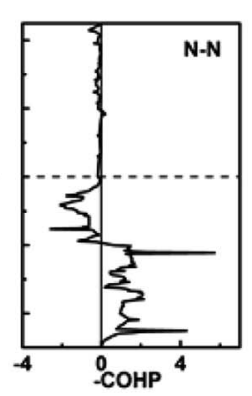

(e)
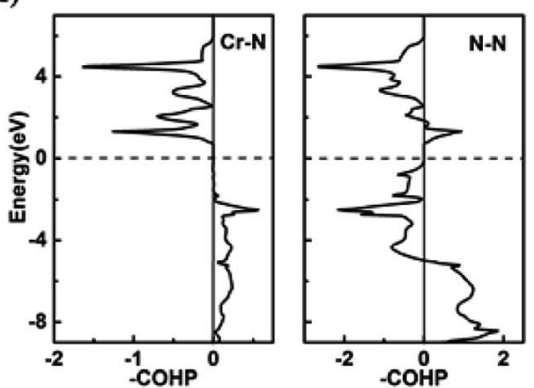

(h)

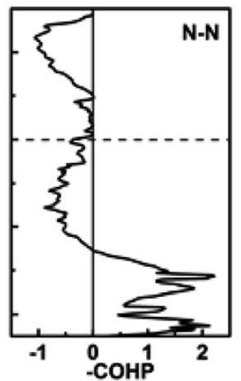

(b)
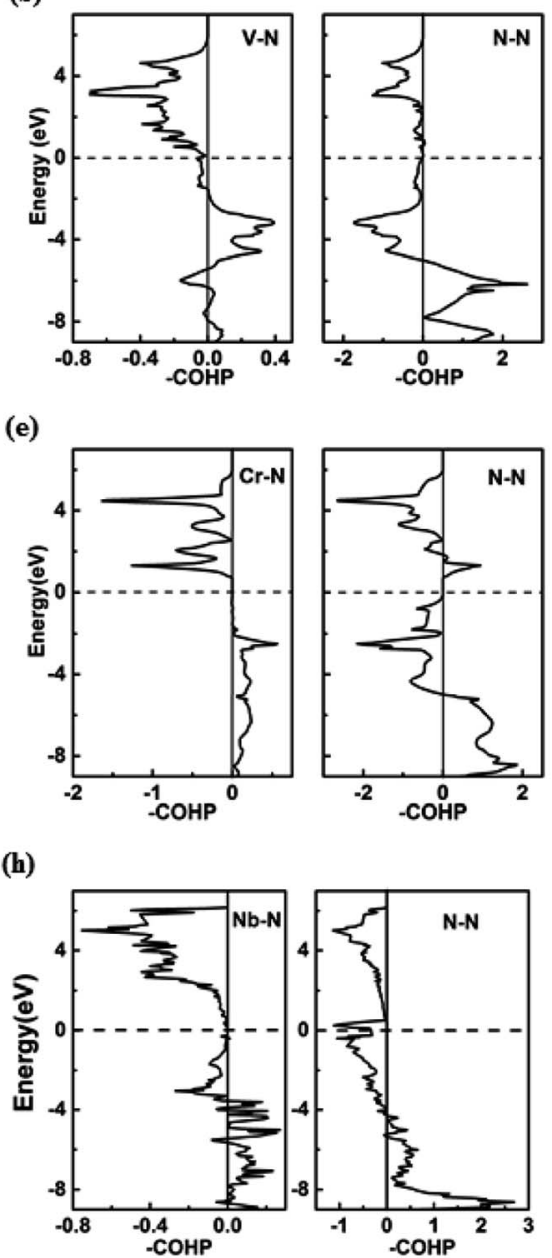

(c)

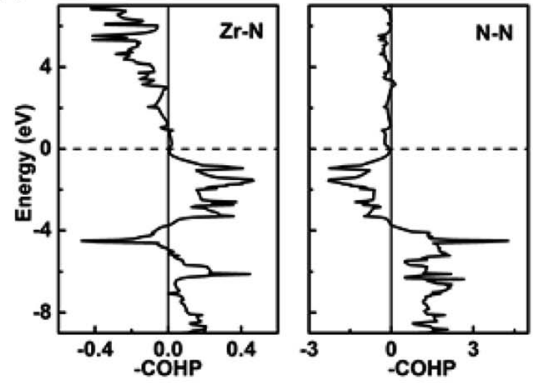

(f)

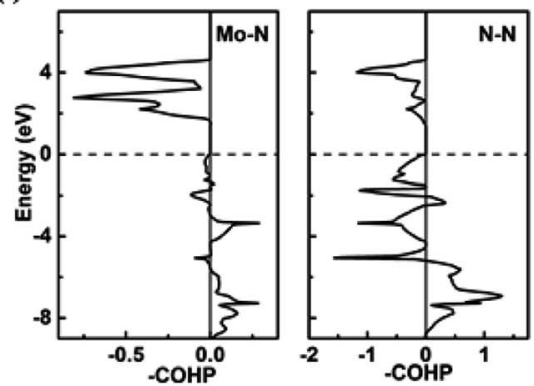

(i)

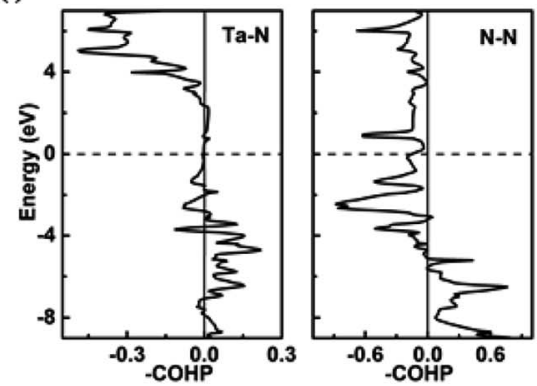

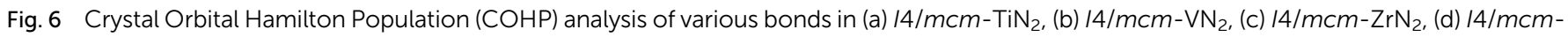
$\mathrm{HfN}_{2}$, (e) $P 6_{3} / m m c-C r N_{2}$, (f) $P 6_{3} / m m c-M o N_{2}$, (g) $P 1-M n N_{2}$, (h) $C c-N b N_{2}$, and (i) $C m c a-T_{a N}$ at ambient pressure. The Fermi level (EF) is marked by gray dashed line.

second value (35.6 GPa). The $\mathrm{NbN}_{2}$ and $\mathrm{TaN}_{2}$ on the other hand have very low hardness as what one would expect for metals. The high hardness in $\mathrm{MnN}_{2}$ is facilitated by the formation of three-dimensional (3D) covalent networks driven by hybridizations of $\mathrm{N}-\mathrm{p}$ and TM-d electrons. For $\mathrm{VN}_{2}$, the hardness is associated to the short V-N bonds: the $\mathrm{V}-\mathrm{N}$ bonds is $2.133 \AA$ at ambient pressure, even shorter than the Ti-N bond (2.201 $\mathrm{A})$ in the isostructural $\mathrm{TiN}_{2}$, a known hard material. In the case of isostructural pernitrides, clearly there is a correlation between the hardness and the strength of the covalent bonds. The calculated bulk $(B)$, shear $(G)$, Young's $(E)$ moduli and Poisson's ratio for predicted $\mathrm{TMN}_{2}$ pernitrides are presented in Table 2 and compared with the previous theoretical or experimental results available. The results agree well with the reported theoretical values, demonstrating the reliability of the present calculations. Pugh's ratio $(G / B)$ and Poisson's ratio $\left(P_{\mathrm{r}}\right)$ are the factors which describe the ductile/brittle nature of a material. In 1954 , Pugh $^{43}$ has proposed that a high value $(>0.57)$ is associated with brittleness and a low value $(<0.57)$ indicates the ductile nature of materials. Frantsevich et al. ${ }^{\mathbf{4 4}}$ has also separated the ductility and brittleness of a material in terms of Poisson's ratio
$\left(P_{\mathrm{r}}\right)$ and suggested that if the Poisson's ratio is less than 0.26 then the material will be brittle otherwise the material will be ductile. The calculated Pugh's ratios and Poisson's ratio show that all predicted $\mathrm{TMN}_{2}$ pernitrides are intrinsically brittle

Table 2 Calculated zero-pressure bulk modulus $B$, shear modulus $G$, Young's modulus $E$, Pugh's ratio $(G / B)$ and Poisson's ratio $\left(P_{r}\right)$ of the studied TM pernitrides. Comparison is made to previously reported results where possible

\begin{tabular}{lllllll}
\hline Crystal & Phases & $B$ & $G$ & $G / B$ & $E$ & $P_{\mathrm{r}}$ \\
\hline TiN $_{2}$ & $I 4 / m c m$ & 288 & 220 & 0.763 & 525 & 0.196 \\
Other theory $^{19}$ & $I 4 / m c m$ & 284 & 197 & 0.693 & 481 & 0.218 \\
Expt. $^{7}$ & $I 4 / m c m$ & 385 & & & & \\
$\mathrm{VN}_{2}$ & $I 4 / m c m$ & 324 & 225 & 0.698 & 550 & 0.217 \\
$\mathrm{ZrN}_{2}$ & $I 4 / m c m$ & 270 & 175 & 0.647 & 432 & 0.234 \\
$\mathrm{HfN}_{2}$ & $I 4 / m c m$ & 294 & 204 & 0.693 & 497 & 0.219 \\
$\mathrm{CrN}_{2}$ & $P 6_{3} / m m c$ & 344 & 245 & 0.710 & 593 & 0.213 \\
Other theory $^{21}$ & $P 6_{3} / m m c$ & 326 & 231 & 0.709 & 561 & \\
$\mathrm{MoN}_{2}$ & $P 6_{3} / m m c$ & 339 & 211 & 0.622 & 525 & 0.242 \\
Other theory $^{18}$ & $P 6_{3} / m m c$ & 338 & 206 & & & \\
$\mathrm{MnN}_{2}$ & $P \overline{1}$ & 306 & 206 & 0.674 & 505 & 0.225 \\
$\mathrm{NbN}_{2}$ & $C c$ & 263 & 102 & 0.388 & 271 & 0.328 \\
TaN $_{2}$ & $C m c a$ & 340 & 193 & 0.569 & 488 & 0.261
\end{tabular}


except the two metallic ones $\left(\mathrm{NbN}_{2}\right.$ and $\left.\mathrm{TaN}_{2}\right)$. The obtained bulk modulus for $\mathrm{TiN}_{2}$ is $288 \mathrm{GPa}$, which is consistent to the theoretical value $(284 \mathrm{GPa})$ predicted by $\mathrm{Yu}$ et $a l .{ }^{19}$ but substantially lower than the measured values (360-385 GPa). ${ }^{7}$ In view of the discrepancy, the experimental uncertainties in fitting the EOS and density functional calculation errors in estimating the crystal volumes should be both taken into consideration. In general, the predicted $\mathrm{TMN}_{2}$ pernitrides have high bulk moduli close to that of $\operatorname{IrN}_{2}(B=327 \mathrm{GPa}), \mathrm{PtN}_{2}(B=$ $272 \mathrm{GPa})$ and $\mathrm{OsN}_{2}(B=359 \mathrm{GPa}),{ }^{3,23}$ indicating that these materials are highly incompressible. From Table 2 one can also see that for isostructural pernitrides, $\mathrm{TiN}_{2}, \mathrm{VN}_{2}, \mathrm{ZrN}_{2}$ and $\mathrm{HfN}_{2}$, the highest bulk modulus goes to $\mathrm{VN}_{2}$ which has the shortest TM-N distances. The correlation between the bulk modulus and bondlength may be understood from the charge transfer from TM to $\mathrm{N}$. The charge transfer influences the dinitrogen bond strength by increasing Coulomb repulsion between two $\mathrm{N}$ atoms and populating the antibonding $1 \pi_{\mathrm{g}}^{*}$ states, which jointly lead to the elongation of $\mathrm{N}-\mathrm{N}$ bond and destabilization of the $\mathrm{N}_{2}$ units. Interestingly, $\mathrm{MnN}_{2}$ exhibits the highest Vickers hardness (36.6 GPa) among all pernitrides but only have a moderate bulk modulus (306 GPa), suggesting that the estimate of hardness goes far beyond the bulk modulus.

\section{Conclusions}

In summary, we have carried out a thorough investigation of transition metal (TM) pernitrides using the CALYPSO global structure search method and predicted/determined the groundstate crystal structures of $\mathrm{TiN}_{2}, \mathrm{VN}_{2}, \mathrm{CrN}_{2}, \mathrm{MnN}_{2}, \mathrm{HfN}_{2}, \mathrm{NbN}_{2}$, $\mathrm{MoN}_{2}, \mathrm{ZrN}_{2}$, and $\mathrm{TaN}_{2}$ in the pressure range of 0-100 GPa. The structures obtained for $\mathrm{TiN}_{2}, \mathrm{CrN}_{2}$ and $\mathrm{MoN}_{2}$ known previously compare well with the available experimental and theoretical results reported in literature. For $\mathrm{VN}_{2}, \mathrm{ZrN}_{2}, \mathrm{HfN}_{2}, \mathrm{MnN}_{2}, \mathrm{NbN}_{2}$ and $\mathrm{TaN}_{2}$, which have yet to be synthesized, the predicted structures and properties can be used as a guide for future synthesis and theoretical studies. Phonon dispersion relation and formation enthalpy calculations suggest that the predicted $\mathrm{TMN}_{2}$ pernitrides are all thermodynamic and dynamically stable at ambient conditions, which provides a good possibility that they can be quench recovered once synthesized under high pressure conditions. Similar to $\mathrm{PtN}_{2}$, the predicted TM pernitrides have extraordinary mechanic properties including high bulk modulus and Vickers hardness which are originated from the single nature of $\mathrm{N}-\mathrm{N}$ bond in $\left[\mathrm{N}_{2}\right]^{4-}$ pernitride unit and the TM-N charge transfer. New results obtained in the present study push forward the understanding of the crystal structures and electronic properties of transition metal pernitrides at high pressures.

\section{Conflicts of interest}

The authors declare no competing financial interest.

\section{Acknowledgements}

This work was supported by NSAF (No. U1530124), the National Natural Science Foundation of China (No. 11474128), Science
Challenge Project (No. TZ2016001), Program for JLU Science and Technology Innovative Research Team and Natural Sciences and Engineering Research Council of Canada (NSERC).

\section{References}

1 E. Gregoryanz, C. Sanloup, M. Somayazulu, J. Badro, G. Fiquet, H. K. Mao and R. J. Hemley, Nat. Mater., 2004, 3, 294.

2 J. C. Crowhurst, A. F. Goncharov, B. Sadigh, C. L. Evans, P. G. Morrall, J. L. Ferreira and A. J. Nelson, Science, 2006, 311, 1275.

3 A. F. Young, C. Sanloup, E. Gregoryanz, S. Scandolo, R. J. Hemley and H. K. Mao, Phys. Rev. Lett., 2006, 96, 155501.

4 J. C. Crowhurst, A. F. Goncharov, B. Sadigh, J. M. Zaug, D. Aberg, Y. Meng and V. B. Prakapenka, J. Mater. Res., 2008, 23, 1.

5 K. Niwa, K. Suzuki, S. Muto, K. Tatsumi, K. Soda, T. Kikegawa and M. Hasegawa, Chem.-Eur. J., 2014, 20, 13885.

6 K. Niwa, D. Dzivenko, K. Suzuki, R. Riedel, I. Troyan, M. Eremets and M. Hasegawa, Inorg. Chem., 2014, 53, 697.

7 V. S. Bhadram, D. Y. Kim and T. A. Strobel, Chem. Mater., 2016, 28, 1616.

8 D. Laniel, A. Dewaele and G. Garbarino, Inorg. Chem., 2018, $57,6245$.

9 A. F. Young, J. A. Montoya, C. Sanloup, M. Lazzeri, E. Gregoryanz and S. Scandolo, Phys. Rev. B, 2006, 73, 153102.

10 R. Yu, Q. Zhan and L. C. Angew, Angew. Chem., Int. Ed., 2007, 46, 1136-1140.

11 D. Åberg, B. Sadigh, J. Crowhurst and A. F. Goncharov, Phys. Rev. Lett., 2008, 100, 095501.

12 Z. J. Wu, E. J. Zhao, H. P. Xiang, X. F. Hao, X. J. Liu and J. Meng, Phys. Rev. B, 2007, 76, 054115.

13 E. Zhao and Z. Wu, Comput. Mater. Sci., 2008, 44, 531.

14 Y. Li and Z. Zeng, Chem. Phys. Lett., 2009, 474, 93.

15 X. P. Du, Y. X. Wang and V. C. Lo, Phys. Lett. A, 2010, 374, 2569.

16 F. Kawamura, H. Yusa and T. Taniguchi, Appl. Phys. Lett., 2012, 100, 251910.

17 S. M. Wang, H. Ge, S. L. Sun, J. Z. Zhang, F. M. Liu, X. D. Wen, X. H. Yu, L. P. Wang, Y. Zhang and H. W. Xu, J. Am. Chem. Soc., 2015, 137, 4815-4822.

18 S. Y. Yu, B. Huang, X. J. Jia, Q. F. Zeng, A. R. Oganov, L. T. Zhang and G. Frapper, J. Phys. Chem. C, 2016, 120, 11060.

19 S. Yu, Q. Zeng, A. R. Oganov, G. Frapper and L. Zhang, Phys. Chem. Chem. Phys., 2015, 17, 11763.

20 S. Y. Yu, Q. F. Zeng, A. R. Oganov, G. Frapper, B. Huang, H. Y. Niu and L. T. Zhang, RSC Adv., 2017, 7, 4697.

21 Z. L. Zhao, K. Bao, F. B. Tian, D. F. Duan, B. B. Liu and T. Cui, Phys. Rev. B, 2016, 93, 214104.

22 Z. L. Zhao, K. Bao, F. B. Tian, D. F. Duan, B. B. Liu and T. Cui, Phys. Chem. Chem. Phys., 2015, 17, 22837.

23 M. G. Zhang, K. Cheng, H. Y. Yan, Q. Wei and B. B. Zheng, Sci. Rep., 2016, 6, 36911.

24 G. Soto, Comput. Mater. Sci., 2012, 61, 1-5. 
25 H. Y. Yan, M. G. Zhang, Q. Wei and P. Guo, J. Alloys Compd., 2013, 581, 508-514.

26 Z. T. Y. Liu, D. Gall and S. V. Khare, Phys. Rev. B, 2014, 90, 134102.

27 J. Zhou, Z. M. Sun and R. Ahuja, J. Alloys Compd., 2009, 472, 425-428.

28 W. Kohn and L. J. Sham, Phys. Rev., 1965, 140, A1133.

29 G. Kresse and J. Hafner, Phys. Rev. B, 1993, 47, 558-561.

30 G. Kresse and J. Furthmüller, Phys. Rev. B, 1996, 54, 1116911186.

31 P. E. Blöchl, Phys. Rev. B, 1994, 50, 17953-17979.

32 J. P. Perdew, K. Burke and M. Ernzerhof, Phys. Rev. Lett., 1996, 77, 3865-3868.

33 Y. Wang, J. Lv, L. Zhu and Y. Ma, Phys. Rev. B, 2010, 82, 094116.

34 Y. Wang, J. Lv, L. Zhu and Y. Ma, Comput. Phys. Commun., 2012, 183, 2063-2070.

35 A. Togo, F. Oba and I. Tanaka, Phys. Rev. B: Condens. Matter, 2008, 78, 134106.
36 R. Hill, Proc. Phys. Soc., London, 1952, A65, 349.

37 V. L. Deringer, A. L. Tchougréeff and R. Dronskowski, J. Phys. Chem. A, 2011, 115, 5461-5466.

38 M. Stefan, V. L. Deringer, A. L. Tchougréeff and R. Dronskowski, J. Comput. Chem., 2013, 34, 2557-2567.

39 M. Wessel and R. Dronskowski, J. Am. Chem. Soc., 2010, 132, 2421.

40 G. V. Vajenine, G. Auffermann, Y. Prots, W. Schnelle, R. K. Kremer, A. Simon and R. Kniep, Inorg. Chem., 2001, 40, 4866.

41 G. Auffermann, Y. Prots and R. Kniep, Angew. Chem., Int. Ed., 2001, 40, 547.

42 K. Y. Li, X. T. Wang, F. F. Zhang and D. F. Xue, Phys. Rev. Lett., 2008, 100, 235504.

43 S. F. Pugh, Philos. Mag., 1954, 45, 823-843.

44 I. N. Frantsevich, F. F. Voronov and S. A. Bokuta, Elastic Constants and Elastic Moduli of Metals and Insulators Handbook, Naukova Dumka, Kiev, 1983, pp. 60-180. 